\title{
Skeletal health in adult growth hormone deficiency
}

\author{
Nicholas A. Tritos ${ }^{1}$
}

Received: 28 December 2015/ Accepted: 4 January 2016/Published online: 14 January 2016

(C) Springer Science+Business Media New York 2016

It has been several decades since the seminal experimental studies of Harris and Heaney suggested that growth hormone (GH) has a relevant role in skeletal health [1]. Early clinical studies primarily explored the role of $\mathrm{GH}$ replacement in linear bone growth, using GH of human cadaveric origin [2]. At that time, $\mathrm{GH}$ was available in scarce quantities which were rationed for the treatment of GH-deficient children and adolescents. With the availability of recombinant human GH in practically unlimited quantities, it became possible to study the effects of $\mathrm{GH}$ replacement in adults in the past 2 decades. Several studies have shed light on the phenotype of GH-deficient adults and the effects of GH replacement, but have provided relatively limited information regarding the vertebral fracture risk in patients receiving GH replacement.

In the present issue of the Journal, Mazziotti et al. have reported the findings of a prospective study of $40 \mathrm{GH}$-deficient hypopituitary adults who were followed over a 6-year period [3]. They found that $30 \%$ of their patients developed morphometric vertebral fractures during observation. In this study, patients with unreplaced GH deficiency had a significantly higher risk of developing vertebral fractures, even after adjusting for differences in age between GH replaced and unreplaced subgroups. These data affirm and extend previous observations on the effects of $\mathrm{GH}$ on the adult skeleton. Indeed, several retrospective studies have reported an increased risk of fracture (vertebral or all sites combined) among GH-deficient adults in comparison with either the

Nicholas A. Tritos

ntritos@partners.org; ntritos@mgh.harvard.edu

1 Neuroendocrine Unit, Massachusetts General Hospital and Harvard Medical School, Zero Emerson Place \# 112, Boston, MA 02114, USA general population or hypopituitary patients without $\mathrm{GH}$ deficiency [4-6].

What are the possible factors that might account for the increased fracture risk in hypopituitarism? In addition to GH deficiency, these patients may often have other hormone deficiencies, which may influence bone health, either directly (hypogonadism) or indirectly as a consequence of excess replacement therapies (hypoadrenalism and hypothyroidism) [7]. Several lines of evidence, including in vitro, experimental and clinical studies, support the direct relevance of the GH and insulin-like growth factor 1 (IGF-1) axis in skeletal physiology [7]. Lack of GH leads to decreased bone turnover and decreased bone mineral density (BMD) in patients with GH deficiency of adult onset [7]. Whether GH deficiency of childhood onset is similarly associated with decreased BMD in adult life is controversial [8]. In these patients, the validity of dualenergy X-ray absorptiometry (DXA) in assessing BMD can be compromised as a consequence of their smaller bone size, prompting the use of quantitative computed tomography (QCT) in order to yield unbiased estimates of bone density in this population (patients with childhood onset GHD) [8]. Nevertheless, adults with childhood onset GH deficiency also appear to be at increased fracture risk [8].

Based on these considerations, $\mathrm{GH}$ replacement would be anticipated to be beneficial for bone health. Indeed, available data suggest that $\mathrm{GH}$ replacement in adults exceeding 12-18 months in duration raises BMD [9]. Whether the fracture risk decreases in response to $\mathrm{GH}$ replacement has been more difficult to establish definitively, owing to the lack of randomized control clinical trials with fracture endpoints. The present, prospective study provides important data showing a lower risk of vertebral fracture among patients who received GH replacement, and extends the findings of previous retrospective investigations [3]. In the 
current study, the presence of vertebral fracture at study entry (prevalent fracture) increased the risk of incident vertebral fracture. In contrast, baseline lumbar spine BMD did not appear to predict the development of morphometric vertebral fractures, suggesting that critical aspects of bone quality that are crucial to skeletal strength are not captured by densitometric data.

The current prospective study by Mazziotti et al. has led to important, novel insights into the effects of $\mathrm{GH}$ replacement on the adult skeleton [3]. Their data affirm the skeletal benefits of $\mathrm{GH}$ replacement and support the use of this therapy in GH-deficient adults. However, several questions remain unanswered. Ultimately, a randomized clinical trial is needed in order to unequivocally establish the salutary effects of $\mathrm{GH}$ replacement on fracture prevention and quantify the magnitude of the protection from fracture in the central and appendicular skeleton. Such a clinical trial may be feasible and ethical only in countries where adult GH replacement is not currently available. Whether GH replacement decreases the risk of fracture in women as well as in men also needs to be clarified. Indeed, women do not appear to show the same improvement in BMD in response to $\mathrm{GH}$ replacement in many studies [9]. This finding has been attributed to $\mathrm{GH}$ under-replacement in women receiving oral sex steroids, since oral estrogen blunts the effect of GH on hepatic IGF-1 synthesis [9]. However, it appears that this hypothesis may not be sufficient as an explanation for the apparent gender-dimorphic effect of $\mathrm{GH}$ replacement on BMD, since such a gender-dimorphic effect has been observed even in studies where adequate $\mathrm{GH}$ replacement was documented in both women and men, based on the systemic IGF-1 levels during GH replacement [10]. Other issues that require further study include the interaction between $\mathrm{GH}$ replacement and additional pituitary hormone replacement therapies. Furthermore, whether GH replacement may have an additive beneficial effect on fracture risk when administered together or sequentially to other anabolic or antiresorptive therapies will need to be examined.

Like other well-conducted studies, the current article by Mazziotti et al. has not only improved our knowledge but also led us to formulate more provocative questions. It is anticipated that future investigations will further our understanding of the putative protective effects of $\mathrm{GH}$ replacement on the adult skeleton.
Compliance with ethical standards

Conflicts of interest The author has received institution-directed research support from Ipsen, Pfizer, and Novo Nordisk.

\section{References}

1. W.H. Harris, R.P. Heaney, Effect of growth hormone on skeletal mass in adult dogs. Nature 223(5204), 403-404 (1969)

2. M.S. Raben, Treatment of a pituitary dwarf with human growth hormone. J. Clin. Endocrinol. Metab. 18(8), 901-903 (1958)

3. G. Mazziotti, M. Doga, S. Frara, F. Maffezzoni, T. Porcelli, L. Cerri, R. Maroldi, A. Giustina, Incidence of morphometric vertebral fractures in adult patients with growth hormone deficiency. Endocrine (2015). doi:10.1007/s12020-015-0738-z

4. G. Mazziotti, A. Bianchi, S. Bonadonna, M. Nuzzo, V. Cimino, A. Fusco, L. De Marinis, A. Giustina, Increased prevalence of radiological spinal deformities in adult patients with GH deficiency: influence of GH replacement therapy. J. Bone Miner. Res. 21(4), 520-528 (2006)

5. P. Vestergaard, J.O. Jorgensen, C. Hagen, H.C. Hoeck, P. Laurberg, L. Rejnmark, K. Brixen, J. Weeke, M. Andersen, F.L. Conceicao, T.L. Nielsen, L. Mosekilde, Fracture risk is increased in patients with GH deficiency or untreated prolactinomas-a casecontrol study. Clin. Endocrinol. (Oxf) 56(2), 159-167 (2002)

6. C. Wuster, R. Abs, B.A. Bengtsson, H. Bennmarker, U. FeldtRasmussen, E. Hernberg-Stahl, J.P. Monson, B. Westberg, P. Wilton, The influence of growth hormone deficiency, growth hormone replacement therapy, and other aspects of hypopituitarism on fracture rate and bone mineral density. J. Bone Miner. Res. 16(2), 398-405 (2001)

7. G. Mazziotti, S. Chiavistelli, A. Giustina, Pituitary diseases and bone. Endocrinol. Metab. Clin. North Am. 44(1), 171-180 (2015). doi:10.1016/j.ecl.2014.10.014

8. R. Bouillon, E. Koledova, O. Bezlepkina, J. Nijs, E. Shavrikhova, E. Nagaeva, O. Chikulaeva, V. Peterkova, I. Dedov, A. Bakulin, V. Oganov, A.F. Attanasio, Bone status and fracture prevalence in Russian adults with childhood-onset growth hormone deficiency. J. Clin. Endocrinol. Metab. 89(10), 4993-4998 (2004). doi: $10.1210 /$ jc. $2004-0054$

9. M. Barake, A. Klibanski, N.A. Tritos, Effects of recombinant human growth hormone therapy on bone mineral density in adults with growth hormone deficiency: a meta-analysis. J. Clin. Endocrinol. Metab. 99(3), 852-860 (2014). doi:10.1210/jc.20133921

10. M. Elbornsson, G. Gotherstrom, I. Bosaeus, B.A. Bengtsson, G. Johannsson, J. Svensson, Fifteen years of GH replacement increases bone mineral density in hypopituitary patients with adult-onset GH deficiency. Eur. J. Endocrinol. 166(5), 787-795 (2012). doi:10.1530/EJE-11-1072 